18. Межличностная коммуникация : теория и тарного профиля: монография. Самара: Самарский жизнь / О.И. Матьяш и др.; науч. ред. О.И. Матьяш. университет, 2007. 249 с.

СПб.: Речь, 2011. 552 с.

19. Руднева Т.И., Астахова С.В., Лапшова Е.С. Профессиональная подготовка специалистов гумани-

20. Николаева С.В. Методологические подходы к организации дополнительного профессионального образования // Вестник Самарского государственного университета. 2011. № 1-2(82). С. 187-191.

\title{
ACTIVITY SPECIFICS OF EDUCATIONAL INSTITUTIONS PERIPHERAL STAFF IN THE CONDITIONS OF EDUCATION MODERNIZATION
}

(C) 2016

\author{
A.M. Sanko, candidate of pedagogical sciences, \\ associate professor of Theory and Methods of Professional Education Department \\ Samara National Research University, Samara (Russia)
}

Abstract. The following article deals with the change of professional activity content of educational peripheral staff in conditions of higher education modernization and structural changes of historically developed traditions of activity management organization in the higher educational institution in the course of their merger (on the example of two Samara universities merger - higher educational institution that gives education in the sphere of classical natural sciences and humanities and higher educational institution that educates specialists for narrow high-technology, being strategically important for the national defence capability branch). The author describes the content and essence of educational peripheral staff social and technological activity and difficulties appearing at the rearrangement from one activity (communication) to another (work with software programs and services). The author also shows the role of adequate cooperation of educational peripheral staff of all organization departments for activity management effective organization of the university and presents the results of educational peripheral staff activity analysis. The obtained materials can serve as the basis for the interacademic further training courses organization for educational peripheral staff and further monitoring of their activity effectiveness for the educational institution management.

Keywords: innovative activity; educational institutions peripheral staff; professional activity content; interacademic further training; higher education modernization; educational institutions merger; social and technological mobility of specialists.

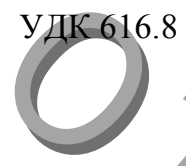

\section{ОСОБЕННОСТИ КОМПЕТЕНТНОСТНОГО ПОДХОДА К РЕАЛИЗАЦИИ СОДЕРЖАНИЯ ОБРАЗОВАНИЯ В ВУЗЕ}

(C) 2016

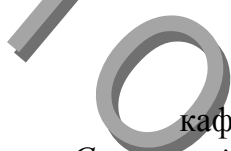

федры ине

Н.Н. Семёнова, старший преподаватель

Самарский государственный сочиально-педагогический университет, Самара (Россия)

Аннотащия. В статье приводятся причины реорганизации системы образования, обновления содержания и технологий образования. Определяются цели современного образования. Приводятся проблемы подготовки будущих педагогов. Рассматриваются проблемы модернизации российской системы образования. Описываются требования к выпускникам образовательных учреждений высшего образования. Раскрываются причины перехода от знаниевой парадигмы образования к компетентностной, рассматривается содержание понятия «компетенция» относительно педагогической деятельности. Анализируются проблемы формирования профессиональных компетенций выпускников вуза по направлению подготовки «Педагогическое образование». Даётся определение компетентностного похода к модернизации содержания профессионального образования. Определяется влияние компетентностного подхода на качество образования. Раскрывается понятие профессиональной компетенции в её взаимосвязи с профессиональной компетентностью педагога и с акцентированием внимания на последнем феномене. Описывается процесс формирования профессиональной компетентности будущего педагога, и анализируются проблемы повышения уровня его профессиональной компетентности. Приводятся группы ключевых компетенций, формируемых у студентов. Даются определения ценностно-смысловых, общекультурных, учебно-познавательных, информационных и қоммуникативных компетенций. Анализируются проблемы внедрения компетентностного подхода в систему образования, раскрывается актуальность и необходимость изменения содержания педагогической деятельности в образовательных учреждениях высшего образования.

Ключевые слова: компетентностный подход; знания; умения; навыки; компетенция; компетентность; цель образования; профессиональные компетенции; ключевые компетенции; ценностно-смысловые компетенции; общекультурные компетенции; учебно-познавательные компетенции; информациөнные компетенции; коммуникативные компетенции.

Трансформация российской действительности в начале XXI века привела к необходимости реорганизации основных социальных институтов, и в первую

очередь системы образования. Это объясняется комплексом социально-экономических причин: обострением опасности потери индивидуальности человека, 
наличием диалектической связи независимости со свободой, невозможностью субъекта усвоить большие потоки информации в виртуальном социуме.

Современная же система образования сложилась в эпоху Нового времени и основана на трансляции содержательного знания о чем-либо. При этом новоевропейская культура базировалась на рациональных началах (каждое знание или каждая деятельность разделяются на последовательность операций), отличалась монологичностью (есть только голос разума, который глаголет истину) и утилитаризмом (всё требует оправдания, а польза сама и есть оправдание).

Обозначенные характеристики культуры экстраполируются в систему ббразования: отрасли знания и отрасли дела порождают урок, специализацию. Последовательность движения знания, развития действия порождает классы - деление учеников по уровню знаний. Монологичность порождает то, что в школе звучит только один голос-голос учителя. Он источник знания. Если это утилитаристская культура, то школа всегда готовит учащихся для чего-то.

Отметим, что для современного образования во всем мире значимой является тенденция к усилению ориентации на субъективный опыт фбучающегося, развитие творчества в сочетании с ответственностью за результат своих действий.

Современному информационному обществу нужны образованные, нравственные, предприимиивые, креативные люди, способные самостоятельно принимать ответственные решения в ситуации выбора, быть мобильными, динамичными, конструктивными специалистами, обладать развитым чувством ответственности.

Думается, что для реализации этой цели необходимо не только обновление содержания и технологий образования, но прежде всего подготовка педагога, способного решать сложные социально-педагогические задачи. Однако изучение результатов некоторых психолого-педагогических и социологических исследований (В.А. Сластенин, В.С. Собкин, Д.В. Адамчук, С.Г. Вершловский) и анализ реальной школьной практики показывают, что профессиональная компетентность современного работника образования и его ментальность [1-4] не в полной мере соответствуют требованиям модернизации российской системы образования [5].

В системе образования традиционно цели определялись набором знаний, умений, навыков (ЗУН), которыми должен владеть выпускник [6]. Сегодня такой подход оказался недостаточным, а социуму, и в первую очередь профессиональным учебным заведениям, производству, семье, требуются выпускники, готовые к включению в дальнейшую жизнедеятельность, способные практически решать встающие перед ними жизненные и профессиональные проблемы. Это, безусловно, во многом зависит как от полученных ЗУНов, так и от неких дополнительных качеств, для обозначения которых и употребляются понятия «компетенция» и «компетентность», более соответствующие пониманию современных целей образования.

Введение этих дефиниций в педагогическую практику требует изменения содержания и методов обучения, уточнения видов деятельности, которыми долж- ны овладеть учащиеся при изучении отдельных предметов.

Социальный заказ общества требует от современного учителя высокой культуры, глубокой нравственности, сформированной системы ценностей и убеждений, гражданской позиции, заинтересованности педагога в развитии творческого потенциала своих учащихся, способности к инновационной деятельности, самосовершенствованию, профессиональной активности и т.д. В связи с этим одной из наиболее актуальных задач для педагогических вузов, наряду с формированием гармонически развитой личности, является проблема подготовки профессионально-компетентностного специалиста.

Поэтому одним из концептуально важных способов управления качеством подготовки выпускников высших учебных заведений является реализация компетентностного подхода к модернизации содержания профессионального образования.

Компетентностный подход означает постепенную переориентацию доминирующей образовательной парадигмы с преимущественной трансляцией знаний и формированием навыков на создание условий для овладения комплексом компетенций, определяющих потенциал и способности выпускника к эффективной, рациональной и устойчивой жизнедеятельности в условиях современного многофакторного социально-политического, рыночно-экономического, информационно и коммуникационно насыщенного пространства.

Проблема повышения уровня профессиональной компетентности будущего учителя, способного свободно и активно мыслить, моделировать воспитательно-образовательный процесс, самостоятельно генерировать ивоплощать новые идеи и технологии обучения и воспитания является особо актуальной в современных социально-экономических условиях. Вопервых, профессионально-компетентностный педагог оказывает позитивное влияние на формирование творческих качеств личности обучающихся в процессе учебно-воспитательной работы; во-вторых, может добиться лучших результатов в своей деятельности; в-третьих, способствует реализации профессиональных возможностей своих учеников.

Определяя содержание понятия «компетентность» относительно педагогической деятельности, В.А. Сластенин предлагает под компетентностью учителя понимать «единство его теоретической и практической готовности к осуществлению педагогической деятельности» [7; с. 174], что характеризует профессионализм педагога. Компетентностный подход в подготовке специалистов требует наличия междисциплинарно-интегрированных требований к результату образовательного процесса. С.В. Тришина и А.В. Хуторской подразумевают под компетентностью кнаперед заданное социальное требование (норму) к образовательной подготовке специалиста, необходимое для его качественной продуктивной деятельности в соответствующей сфере» [8].

Одно из наиболее распространенных определений профессиональной компетентности в отечеетвенной психолого-педагогической литературе звучит следующим образом: «качество, свойство или состояние специалиста, обеспечивающее вместе или в отдельно- 
$\mathrm{C} \longrightarrow \mathrm{H}$

сти его физическое, психическое и духовное соответствие необходимости, потребности, требованиям определенной профессии, специальности, специализации, стандартам квалификации, занимаемой или исполняемой служебной должности» [9, с. 106]. В.П. Беспалько под профессиональной компетентностью понимает совокупность профессиональных знаний, умений, а также способы выполнения профессиональной деятельности [10, с. 96].

Если говорить о профессиональной компетентности педагога $[11-22]$, то в содержание этого понятия вкладывают личные возможности учителя, воспитателя, педагога, позволяющие ему самостоятельно и достаточно эффективно решать педагогические задачи. Необходимым условием для решения тех или иных педагогических задач предполагается знание педагогической теории, умение и готовность применять ее положения на практике. Можно также сказать, что профессиональная компетентность педагога - это сформированность в его труде различных сторон педагогической деятельности и педагогического общения, в которых самореализована личность педагога на уровне, обеспечивающем устойчивые положительные результаты в обучении и развитии учащихся.

Формирование профессиональной компетентности будущего специалиста осуществляется через содержание образования, которое включает в себя не только перечень учебных предметов, но и профессиональные навыки и умения, которые формируются в процессе овладения предметом, а также посредствам активной позиции студента в социальной, политической и культурной жизни. Всё это в комплексе формирует и развивает личность будущего педагога таким образом, чтобы она обладала способами саморазвития и самосовершенствования, что обеспечивало бы педагогу эффективное функционирование как субъекта-профессионала в системе «человек - человек».

Подготовка компетентностного специалиста, соответствующего требованиям сегодняшнего дня, наделенного соответствующими профессиональными качествами, знаниями и умениями, навыками и компетенциями, необходимыми для того, чтобы быть конкурентно- и жизнеспособным, невозможна без построения на научной основе соответствующей системы обучения.

Также следует отметить, что компетентностный подход предполагает формирование у студента некоего набора ключевых компетенций, который позволяют ему успешно продолжать образование каждый раз, когда в этом возникает необходимость, при столкновении с проблемами, появляющимися в личной и профессиональной жизни человека [23, с. 56]. В ходе международного проекта «Определение и отбор ключевых компетентностей» [24], реализуемого Организацией экономического сотрудничества и развития и Национальными институтами образовательной статистики Швейцарии и США, строгого определения ключевых компетенций выработано не было [25]. Опираясь на проведенные исследования А.В. Хуторского [26], нами были определены следующие группы ключевых компетенций.

Ценностно-смысловые компетениии. Это компетенции в сфере мировоззрения, связанные с ценностными ориентирами обучающегося, его способностью видеть и понимать окружающий мир, ориентироваться в нем, осознавать свою роль и предназначение уметь выбирать целевые и смысловые установки для своих действий и поступков, принимать решения. Данные компетенции обеспечивают механизм самоопределения обучающегося в профессиональных ситуациях и иной деятельности. От них зависят индивидуальная образовательная траектория обучающегося и программа его жизнедеятельности в целом.

Общекультурные компетенции. Познание и опыт деятельности в области национальной и общечеловеческой культуры; духовно-нравственные основы жизни человека и человечества, отдельных народов, культурологические основы семейных, социальных, общественных явлений и традиций; роль науки и религии в жизни человека; компетенции в бытовой и культурно-досуговой сферах, например, владение эффективными способами организации свободного времени. Сюда же относится опыт освоения обучающегося научной картины мира, расширяющейся до культурологического и всечеловеческого понимания мира.

Учебно-познавательные компетеничи. Это совокупность компетенций обучающегося в сфере самостоятельной познавательной деятельности, включающей элементы логической, методологической, общеучебной деятельности. Сюда входят способы организации целеполагания, планирования, анализа, рефлексии, самооценки. По отношению к изучаемым объектам обучающийся овладевает креативными навыками продуктивной деятельности: добыванием знаний непосредственно из реальности, владением приемами решения учебно-познавательных проблем, действий в нестандартных ситуациях. В рамках данных компетенций определяются требования функциональной грамотности: умение отличать факты от домыслов, владение измерительными навыками, использование вероятностных, статистических и иных методов познания.

Информационные компетенциии. Навыки деятельности по отношению к информации в учебных предметах и образовательных областях, а также в окружающем мире [27-31]. Владение современными средствами информации (телевизор, магнитофон, телефон, факс, компьютер, принтер, модем, копир и т.п.) и информационными технологиями (аудио-, видеозапись, электронная почта, СМИ, Интернет). Поиск, анализ и отбор необходимой информации, ее преобразование, сохранение и передача.

Коммуникативные компетенции. Знание языков, способов взаимодействия с окружающими и удаленными людьми и событиями, навыки коллективной работы, владение различными социальными ролями [32-37]. Обучающийся должен уметь представить себя, написать письмо, анкету, заявление, задать вопрос, вести дискуссию и др. [38].

Таким образом, подведя итог вышесказанному, можно предположить, что в компетенциях задаются параметры того, что в целом должен уметь и знать, а также на что в профессиональном плане должен претендовать выпускник высшего учебного заведения по его окончании. При этом следует помнить, что компетенции не находятся, как может показаться, в прямой и однозначной привязке к перечню тех знаний и умений, которые приобретает студент в конкретном учебном заведении. Вуз может в настоящее время различными способами достигать цели подготовки выпускника определенного профиля, выбирая и выстраивая по-своему курсы обучения. 


\section{СПИСОК ЛИТЕРАТУРЫ:}

1. Сластенин В.А., Исаев И.Ф., Шиянов Е.Н. Педагогика: учеб. пособие для студ. высш. пед. учеб. заведений / под ред. В.А. Сластенина. М.: Изд. центр «Академия》, 2002. 576 с

2. Собкин В.С., Адамчук Д.В. Современный российский педагог: эскиз к социологическому портрету М.: Центр социологии образования РАО, 2014. 70 с.

3. Собкин В.С., Адамчук Д.В. К вопросу о профессиональном развитии педагога: повышение квалификации и членство в педагогических сообществах. Тюмень: Вестник Тюменского государственного университета. Социально-экономические и правовые исследования, 2015. 180 с.

4. Вершловский С.Г. Общее образование взрослых: Стимулы и мотивы,М., 1987.

5. Концепция модернизации российского образования на период до 2010 года: Приказ Министерства образования РФ от 11.02.2002 № 393 // Учительская газета, 2002. № 31 .

6. Селевко Г.К., СелевкоА.Г. Социально-воспитательные технологии. М, 2000.

7. Сластенин В.А. Реализация новых компетентностных стандартов в образовательном процессе. М.: «Высшее образование», 2011. 329 с.

8. Тришина С.В., Хуторской А.В. Информационная компетентность специалиста в системе дополнительного профессионального образования. [Электронный ресурс] // Интернет-журнал «Эйдос». 2004. 22 июня. - http://eidos.ru/journal/2004/0622-09.htm.

9. Краевский В.В., Хуторской А.В. Предметное общепредметное в образовательных стандартах // Педагогика. 2003. № 3. С. 3-10.

10. Беспалько В.П. Слагаемые педагогической технологии. М.: АСТЭМ, 2010. 433 с.

11. Гудалина Т.А. Содержательная характеристика социально-профессиональной компетентности педагогов специализированных учреждений // Азимут научных исследований: педагогика и психология. 2014. № 4. C. 46-49.

12. Гирка И.В. Формирования профессиональной компетентности у будущих учителей информатики в процессе профессиональной подготовки // Балтийский гуманитарный журнал. 2015. № 2 (11). С. 42-45.

13. Кондаурова И.К., Гусева М.А. Формирование у будущих педагогов-математиков умений и навыков педагога-исследователя в контексте развития профессиональной биографии // Азимут научных исследований: педагогика и психология. 2014. № 4. С. 69-72.

14. Гаврилова М.И., Одарич И.Н. Развитие профессиональной компетентности будущего специалиста как качества личности // Карельский научный журнал. 2015. № 1 (10). С. 36-38.

15. Власенко С.В., Хрущев В.А. Формирование профессиональной компетентности в работе с детьми группы риска студентов специальности «Социальная педагогика и самопознание» // Азимут научных исследований: педагогика и психология. 2015. № 1 (10) С. $18-21$.

16. Смагина А.А. Профессиональная компетентность учителя истории в формировании базовых национальных ценностей у старшеклассников // XXI век: итоги прошлого и проблемы настоящего плюс. 2013. № 8 (12). С. 156-161.

17. Притуляк Л.Н. Особенности формирования профессиональной компетентности будущих воспитате- лей ДНЗ // Балтийский гуманитарный журнал. 2015. № 2 (11). С. 71-74.

18. Коваль В.А. Проблема формирования профессиональной компетентности будущих учителейфилологов в научной среде // Азимут научных исследований: педагогика и психология. 2013. № 4. С. 2023.

19. Богданова А.В., Глазова В.Ф. Технология учебных полей как эффективный инструмент формирования профессиональной компетентности // Карельский научный журнал. 2014. № 2. С. 32-35.

20. Коваль В.А. Периодизация становления профессиональной компетентности будущих учителейфилологов (ретроспективный анализ) // Балтийский гуманитарный журнал. 2013. № 3. С. 15-18.

21. Гаврилова М.И., Одарич И.Н. Профессиональная компетентность бакалавра // Азимут научных исследований: педагогика и психология. 2015. № 1 (10). C. $22-23$.

22. Деревянко Е.В. Формирование профессиональной компетентности будущих горных инженеров в условиях интерактивных технологий обучения // Карельский научный журнал. 2013. № 1. С. 19-22.

23. Митрофанова Е.А. Система формирования информационной компетентности у будущих специалистов. Вольск: изд-во ВПК, 2010. 188 с.

24. Совет Европы: Симпозиум по теме «Ключевые компетенции для Европы»: Док. DECS / SC / Sec. (96) 43. Берн, 1996.

25. Хуторской А.В. Дидактическая эвристика. Теория и технология креативного обучения. М.: Издво МГУ, 2003. 416 с.

26. Хуторской А.В. Технология проектирования ключевых и предметных компетенций [Электронный ресурс] // Интернет-журнал «Эйдос». 2005, 12 декабря. - http://eidos.ru/journal/2005/1212.htm.

27. Темирджанова М.А. Информационная компетентность в предметной и методической системе подготовки студентов к профессиональной деятельности 4 Азимут научных исследований: педагогика и психология. 2014. № 3. С. 71-73.

28. Замара Е.В. Концепция формирования информационной компетентности будущих специалистов по туризму в системе среднего профессионального образования (СПО) // Карельский научный журнал. 2014. № 1. С. 55-59.

29. Богданова А.В. Актуальные вопросы формирования информационно-коммуникативной компетентности у студентов вузов // Азимут научных исследований: педагогика и психология. 2014. № 3. С. 9-13.

30. Богданова А.В. Формирование информационно-коммуникативной комиетентности студентов вуза с применением технологии учебных полей как научная проблема // Балтийский гуманитарный журнал. 2014. № 4. C. 46-50.

31. Замара Е.В. Информационно-технологическая компетентность личности в условия современного среднего профессионального образования // Азимут научных исследований: педагогика и психология. 2014. № 1. С. 29-31.

32. Метелева Л.А. Формирование коммуникативной компетентности как средство развития ситуативной адаптивности студентов в процессе обучения иностранному языку // Балтийский гуманитарный журнал. 2014. № 2. С. 45-47.

33. Метелева Л.А. К вопросу о взаимосвязи социализации и формирования коммуникативной компе- 
тентности студентов в процессе обучения иностранному языку // Азимут научных исследований: педагогика и психолюгия. 2014. № 1. С. 49-51.

34. Павловская Н.Г. Исследование коммуникативной компетентности - аспекта конкурентоспособности будущих бакалавров образования // Карельский научный журнал. 2015. № 2 (11). С. 45-49.

35. Толикина Е.А. Формирование коммуникативной компетенции студентов посредством интегративного курса литературы // Балтийский гуманитарный журнал. 2015. № 3 (12). С. 71-74.

36. Иващенко О.А. Формирование иноязычной коммуникативной компетенции будуших специалистов государственной службы по чрезвычайным ситуациям // Азимут научных исследований: педагогика и психология. 2013. № 1. С. 20-23.

37. Смирнова Е.В. Формирование коммуникативного пространства языковой среды в условиях иноязычного информационного и коммуникационного взаимодействия // Балтийский гуманитарный журнал. 2013. № 2. С. 33-36.

38. Хуторской А.В. Ключевые компетенции и образовательные стандарты [Электронный ресурс] // Интернет-журнал «Эйдос». 2002, 23 апреля. http://eidos.ru/journal/2002/0423.htm.

\section{FEATURES OF A COMPETENCY APPROACH TO THE UNIVERSITY EDUCATION CONTENT IMPLEMENTATION}

(C) 2016

N.N. Semenova, senior lecturer of Information and Communication Technologies in Education Department Samara State University of Social Sciences and Education, Samara (Russia)

Abstract. The following paper deals with the reasons for the reorganization of the educational system, as well as the reasons for updating the content of education and technology. The author describes the goals of modern education, the problems of future teacher training, the problems of the Russian education system modernization, requirements for graduates of higher education institutions, the reasons of the transition from the knowledge and skills to competences, the content of the competence concept with respect to educational activities, the problems of professional competence development at graduates whose major is Teacher Education, the process of future teacher professional competence development. The author states that the competence approach implementation will affect the quality of education. The paper also deals with the problem of raising the level of future teacher professional competence. Crucial competencies are described. The paper contains the definition of professional competence, focusing on the professional competence of the teacher, the definition of value-semantic competence, general cultural competence, educational and cognitive competence, informational competence, communicative competence. The article analyzes the problems of competencebased approach implementation in the educational system, as well as the necessity of educational activities content change in higher education institutions.

Keywords: competence approach; knowledge; skills; competence; the purpose of education; professional competence; crucial competencies; values and sense of competence; general cultural competence; educational and cognitive competence; informational competence; communicative competence.

УДК 378

\section{СРЕДСТВА УПРАВЛЕНИЯ КАЧЕСТВОМ САМОСТОЯТЕЛЬНОЙ РАБОТЫ СТУДЕНТОВ}

(C) 2016

Н.Б. Стрекалова, кандидат педагогических наук,

доцент кафедры теории и методики профессионального образования

Самарский наџиональный исследовательский университет имени академика С.П. Королёва, Самара (Россия)

Аннотация. В статье рассматривается самостоятельная работа студентов как важный фактор высшего образования. Описываются специфика и особенности выполнения самостоятельной работы студентов в условиях электронного обучения, расширения дистантных форм обучения и переноса учебного процесса в Интернет. Определяется суть самостоятельной работы студентов и влияния на нее образовательных рисков разной природы. С опорой на международные стандарты ИСО, определяющие главную задачу обеспечения качества как управление возникающими в ходе его достижения рисками, делается вывод о возможности обеспечения качества самостоятельной работы студентов педагогическими средствами управления. Поиск педагогических средств управления качеством самостоятельной работы студентов осуществлялся на базе Тольяттинской академии управления, в которой опыт применения открытой информационно-образовательной среды составляет более 10 лет. Результаты исследования показали, что эффективное управление качеством самостоятельной работы студентов в новых условиях протекания учебного процесса требует осуществления трех разных видов управления: опосредованного педагогического, самоуправления студентом и совместного управления преподавателя и студента - и, соответственно, разных педагогических средств. Полученные материалы могут служить основой для повышения качества не только самостоятельной работы студентов, но и высшего образования в целом.

Ключевые слова: самостоятельная работа студентов; управление; управленческая триада; опосредованное педагогическое управление; самоуправление; соуправление; образовательные риски; средовой подход; партисипативное управление; субъектность; полисубъект; открытая образовательная среда. 